\title{
EFFECTS OF SOME PLANT EXTRACTS ON SOME BIOLOGICAL PARAMETERS OF CATFISH Clarias gariepinus (Burchell 1822)
}

\author{
${ }^{1}$ R.N. OLADOSU-AJAYI; ${ }^{2}$ F.O.A. GEORGE; ${ }^{2}$ S.O. OBASA, AND ${ }^{3}$ M.O. BANKOLE \\ ${ }^{1}$ Department of Fisheries Technology, FCFFT, New Bussa. Niger State \\ ${ }^{2}$ Department of Aquaculture and Fisheries Mgt., University of Agriculture, Abeokuta. Ogun State \\ ${ }^{3}$ Department of Microbiology, University of Agriculture, Abeokuta. Ogun State
}

Copyright 2010, Fisheries Society of Nigeria.

This paper was prepared for presentation at the $25^{\text {th }}$ Annual International Conference and Exhibition in Administrative Staff College of Nigeria (ASCON), Topo-Badagry, Lagos, Nigeria, $25^{\text {th }}-29^{\text {th }}$ October, 2010

This paper was selected for presentation by an FISON Program Committee following review of information contained in an abstract submitted by the author(s). Contents of the paper, as presented, have not been reviewed by the Fisheries Society of Nigeria and are subject to correction by the author(s). The material, as presented, does not necessarily reflect any position of the Fisheries Society of Nigeria, its officers, or members. Papers presented at FISON meetings are subject to publication review by Editorial Committees of the Fisheries Society of Nigeria. Electronic reproduction, distribution, or storage of any part of this paper for commercial purposes without the written storage of any part of this paper for commercial purposes without the written consent of the Fisheries Society of Nigeria is prohibited. Permission to reproduce in print is restricted to an abstract of not more than 300 words; illustrations may not be copied. The abstract must contain conspicuous acknowledgement of where and by whom the paper was presented. Write Librarian, Fisheries Society of Nigeria (FISON), P. O. Box 2607 Apapa,
Lagos.

\section{ABSTRACT}

Preliminary studies on the antimicrobial properties of various methods of extraction of Carica papaya (Pawpaw) seeds, Citrus paradisa (Grapefruit peel) and Piper guineese (Black pepper) seeds against eleven bacteria ( Proteus mirabilis, Escherichia coli, Staphylococcus aureus, Acinetobacter sp, Klebsiella pneumoniae, K. oxytoca, Pseudomonas lundensis, Bacillus subtilis, B. megaterium, Citrobacter freundii and Enterobacter cloacae) associated with fresh catfish spoilage were investigated using the cupplate diffusion method. Cold water, hot water and ethanol were the different extraction solvents used while the concentrations were $0.1 \mathrm{~g} / \mathrm{ml}, 0.2 \mathrm{~g} / \mathrm{ml}$, $0.3 \mathrm{~g} / \mathrm{ml}, 0.4 \mathrm{~g} / \mathrm{ml}$ and $0.5 \mathrm{~g} / \mathrm{ml}$. Generally, hot water extraction of the plant materials was most effective $(p<0.01)$ with the highest mean zone of inhibition of $4.42 \pm$ $0.38 \mathrm{~mm}$ followed by ethanol extraction $(3.55 \pm 0.47 \mathrm{~mm})$. The most susceptible bacteria was Enterobacter cloacae with the highest mean zone of inhibition of 22.6 $\pm 3.50 \mathrm{~mm}$. This investigation indicates that the antimicrobial compounds in grape peel and black pepper are best liberated when extracted with ethanol while that of pawpaw is best extracted with hot water.

Keywords: Antimicrobial properties, Carica papaya (Pawpaw), Citrus paradisa (grape peel), Piper guineese (Black pepper), Cup-plate diffusion.

\section{INTRODUCTION}

Food spoilage is a metabolic process that causes food to be undesirable or unacceptable for human consumption due to changes in sensory and nutritional characteristics (Doyle, 2007). Fish is a very perishable, high-protein food that typically contains high levels of free amino acids. Spoilage organisms differ for fish depending on their habitat [fresh or marine] and locality [tropical or temperate]. Fish is a very high protein source whose demand is very high, more than what the local production can meet. Despite the inability of the local fish production to meet the corresponding demand, large quantity of this locally produced fish is lost to post-harvest losses. Natural preservative methods are thus abandoned for the synthetic methods which have been discovered to have adverse effects on the health of the final consumers of such fish, e.g. health challenges like cancer, lung problems e.t.c. The grapefruit is a subtropical citrus tree grown for its fruit. All parts of the fruit have uses. The fruit is mainly consumed for a tangy juice (Fellers et. al. 1990). The antimicrobial efficacy of grapefruit is tested by extracting the active ingredients in it by using glycerin in the extraction method (Woedtke et. al., 1999). The pawpaw is a deciduous, often narrowly conical tree growing from about 12 feet to 
around 20 feet. Pawpaw trees are prone to producing root suckers a few feet from the trunk. The ripe fruit is soft thin skinned. Although pawpaw peel is not edible, its seeds are. Pawpaw seeds resemble large peppercorns and also have a peppery taste (De La Cruz Medina et. al., 2003). Pawpaw contains antimicrobial compounds like tannin, terpenoids, alkaloids, and organic acids. Black pepper is a flowering vine in the family Piperaceae, cultivated for its fruit, which is usually dried and used as a spice and seasoning. In dried form, the fruit is often referred to as peppercorns. Pepper gets its spicy heat mostly from the piperine compound which has some antimicrobial properties and is found both in the outer fruit and in the seed.

\section{MATERIALS AND METHODS Test Organism Confirmation}

Test organisms were isolated from the mouth, flesh, skin, gills and gut of freshly caught and slaughtered Clarias gariepinus (catfish) from a landing site in Abeokuta. The pure cultures were subcultured on Nutrient Agar slants and preserved in the refrigerator at $4^{\circ} \mathrm{C}$ until required for the study.

\section{Collection of Plant materials}

The plant materials, grape fruit (Citrus paradisa) peel, Pawpaw (Carica papaya) and Black pepper (Piper guineese) seeds were collected from Adatan market in Abeokuta.

\section{Extraction of the Plants \\ Grape peel Extraction}

The grape was washed with clean water, peeled and the separation and extraction done in the following ways:

1. $300 \mathrm{~g}$ of grape peel was blended into fine powder and soaked in $150 \mathrm{mls}$ of cold distilled water for $1 \mathrm{hr}$. The pulp obtained was left in clean, sterile glass container and shaken vigorously to allow for proper extraction. Filtration was done using a sterile muslin cloth after which the extract obtained was stored at ambient temperature until required (Azu and Onyeagba, 2007).

2. $300 \mathrm{~g}$ of grape peel was blended and soaked in $150 \mathrm{mls}$ of hot water for $1 \mathrm{hr}$; the resultant juice extracted was stored as done in (1) above.

3. $300 \mathrm{~g}$ of grape peel was blended and soaked in $150 \mathrm{mls}$ of $95 \%$ ethanol for $1 \mathrm{hr}$; the resultant juice extracted was stored as done in (1) above.

\section{Antimicrobial Screening Test}

The sensitivity of the test organisms, Proteus mirabilis, Escherichia coli, Staphylococcus aureus, Acinetobacter sp, Klebsiella pneumoniae, $K$. oxytoca, Pseudomonas lundensis, Bacillus subtilis, B. megaterium, Citrobacter freundii and Enterobacter cloacae to the extracts of grape fruit (Citrus paradisa) peel, Pawpaw (Carica papaya) and Black pepper (Piper guineese) seeds was carried out using the cup-plate diffusion method. $1 \mathrm{ml}$ of each organism was inoculated into tubes of sterilized nutrient agar which has cooled to $45^{\circ} \mathrm{C}$. This was mixed properly and poured into sterile Petri dishes, allowing them to solidify. Holes of $15 \mathrm{~mm}$ in diameter were made in the agar using sterile cork borer.

\section{Statistical Analysis}

Data obtained in the study were statistically analyzed using Analysis of Variance (ANOVA). The means were separated using Fisher's Least Significant Difference (LSD) (Sanders, 1990). 


\section{RESULTS AND DISCUSSION}

Table 1: Significance of extract concentration on the sensitivity of the isolated organisms

\begin{tabular}{|c|c|c|c|c|c|}
\hline \multirow{3}{*}{ Micro organisms } & \multirow{2}{*}{\multicolumn{5}{|c|}{ Extract Concentration $(\mathrm{g} / \mathrm{ml})$}} \\
\hline & & & & & \\
\hline & 0.1 & 0.2 & 0.3 & 0.4 & 0.5 \\
\hline cinetobacter $s$ & $2.22+1.78$ & $3.78 \pm 2$ & $2.33 \pm 1.31$ & $2.22 \pm 1.28$ & $1.67 \pm 1.13$ \\
\hline Bacillus $n$ & $0.33 \pm 0$ & 2.00 & $3+$ & $3.44 \pm$ & $2.44 \pm 2.10$ \\
\hline Escherichia coli & $2.33 \pm 1.65$ & $3.33 \pm$ & $2.67 \pm$ & $2.00 \pm$ & $0.33 \pm 0.33$ \\
\hline Bacillus subtilis & $1.78 \pm 1.44$ & $1.33 \pm$ & $1.56+($ & $2.44 \pm$ & $3.67 \pm 1.50$ \\
\hline Citrobac & $2.44 \pm 1.04$ & 3.56 & $4.78 \overline{ \pm}$ & $3.89=$ & $4.33 \pm 2.14$ \\
\hline Enter & $2.44 \pm$ & $3.56=$ & $5.22 \pm$ & $5.67=$ & $8.67 \pm 3.79$ \\
\hline Klebsiella pr & & $3.22 \pm$ & $4.56 \pm 2$ & & \pm 3.83 \\
\hline Klebsiella ox & $0.89 \pm 0.89$ & $1.67 \pm 0.97$ & $2.11+1.06$ & $2.67 \pm 1.21$ & $4.11 \pm 1.60$ \\
\hline Prote & & $2.11 \pm 0.75$ & $3.00 \pm 1.20$ & $3.44 \pm 1.28$ & $4.89 \pm 1.33$ \\
\hline Pseudomonas lundensis & $1.78 \pm 0.97$ & $1.78 \pm 0.92$ & $1.77 \pm 0.89$ & $2.56 \pm 1.30$ & $2.78 \pm 1.41$ \\
\hline Staphylococcus aureus & $1.44 \pm 0.90$ & $1.7 \overline{8} \pm 0.92$ & $2 . \overline{44}+1.24$ & $3.00 \pm 1.51$ & $4.00 \pm 2.0$ \\
\hline
\end{tabular}

Table 2: Combined effects of plant source and respective methods of extraction on the inhibition zones of spoilage organisms in fish

\begin{tabular}{|c|c|c|c|c|}
\hline \multirow[t]{2}{*}{ Micro organisms } & \multicolumn{4}{|c|}{ Extraction Method } \\
\hline & Plant & Ethanol & Hot water & Cold water \\
\hline \multirow[t]{3}{*}{ Acinetobacter species } & Grape & $0.00 \pm 0.00$ & $3.20 \pm 1.66$ & $0.00 \pm 0.00$ \\
\hline & Pawpaw & $0.00 \pm 0.00$ & $12.00 \pm 3.78$ & $0.00 \pm 0.00$ \\
\hline & Black pepper & $0.00 \pm 0.00$ & $6.80 \pm 1.24$ & $0.00 \pm 0.00$ \\
\hline \multirow[t]{3}{*}{ Bacillus megaterium } & Grape & $0.00 \pm 0.00$ & $10.20 \pm 3.34$ & $0.00 \pm 0.00$ \\
\hline & Pawpaw & $0.00 \pm 0.00$ & $6.00 \pm 2.00$ & $0.00 \pm 0.00$ \\
\hline & Black pepper & $0.00 \pm 0.00$ & $3.20 \pm 1.66$ & $0.00 \pm 0.00$ \\
\hline \multirow[t]{3}{*}{ Escherichia coli } & Grape & $0.00 \pm 0.00$ & $5.60 \pm 2.69$ & $0.00 \pm 0.00$ \\
\hline & Pawpaw & $0.00 \pm 0.00$ & $10.60 \pm 3.30$ & $0.00 \pm 0.00$ \\
\hline & Black pepper & $0.00 \pm 0.00$ & $3.00 \pm 1.14$ & $0.00 \pm 0.00$ \\
\hline \multirow[t]{3}{*}{ Bacillus subtilis } & Grape & $3.40 \pm 1.21$ & $0.00 \pm 0.00$ & $0.00 \pm 0.00$ \\
\hline & Pawpaw & $6.00 \pm 1.41$ & $2.60 \pm 1.66$ & $0.00 \pm 0.00$ \\
\hline & Black pepper & $7.40 \pm 1.44$ & $0.00 \pm 0.00$ & $0.00 \pm 0.00$ \\
\hline \multirow[t]{3}{*}{ Citrobacter freundii } & Grape & $5.00 \pm 0.84$ & $6.00 \pm 0.00$ & $2.80 \pm 0.86$ \\
\hline & Pawpaw & $0.00 \pm 0.00$ & $6.00 \pm 0.00$ & $0.00 \pm 0.00$ \\
\hline & Black pepper & $0.00 \pm 0.00$ & $6.00 \pm 0.00$ & $0.00 \pm 0.00$ \\
\hline \multirow[t]{3}{*}{ Enterobacter cloacae } & Grape & $9.60 \pm 2.79$ & $7.20 \pm 2.27$ & $5.00 \pm 0.55$ \\
\hline & Pawpaw & $2.80 \pm 1.24$ & $0.00 \pm 0.00$ & $0 . \overline{00} \pm 0.00$ \\
\hline & Black pepper & $22.60 \pm 3.50$ & $0.00 \pm 0.00$ & $0.00 \pm 0.00$ \\
\hline \multirow[t]{3}{*}{ Klebsiella pneumoniae } & Grape & $14.60 \pm 4.95$ & $9.40 \pm 4.12$ & $6.20 \pm 2.84$ \\
\hline & Pawpaw & $2.20 \pm 1.36$ & $0 . \overline{00} \pm 0.00$ & $0 . \overline{0} 0 \pm 0.00$ \\
\hline & Black pepper & $9.80 \pm 4.31$ & $0.00 \pm 0.00$ & $0.00 \pm 0.00$ \\
\hline \multirow[t]{3}{*}{ Klebsiella oxytoca } & Grape & $2.40 \pm 0.98$ & $2.00 \pm 0.63$ & $3.60 \pm 1.36$ \\
\hline & Pawpaw & $2.20 \pm 1.02$ & $0.0 \overline{0} \pm 0.00$ & $0.00 \pm 0.00$ \\
\hline & Black pepper & $10.4 \pm 1.03$ & $0.00 \pm 0.00$ & $0.00 \pm 0.00$ \\
\hline \multirow[t]{3}{*}{ Proteus mirabilis } & Grape & $4.60 \pm 1.17$ & $4.80 \pm 0.97$ & $2.20 \pm 0.66$ \\
\hline & Pawpaw & $5.80 \pm 0.80$ & $0.00 \pm 0.00$ & $0.00 \pm 0.00$ \\
\hline & Black pepper & $8.20 \pm 0.80$ & $0.00 \pm 0.00$ & $0.00 \pm 0.00$ \\
\hline Pseudomonas lundensis & Grape & $0.00 \pm 0.00$ & $6.60 \pm 1.08$ & $0.00 \pm 0.00$ \\
\hline
\end{tabular}




\begin{tabular}{|c|c|c|c|c|}
\hline \multirow{5}{*}{ Staphylococcus aureus } & Pawpaw & $0.00 \pm 0.00$ & $7.20 \pm 0.66$ & $0.00 \pm 0.00$ \\
\hline & Black pepper & $0.00 \pm 0.00$ & $5.40 \pm 0.75$ & $0.00 \pm 0.00$ \\
\hline & Grape & $0.00 \pm 0.00$ & $7.80 \pm 2.01$ & $0.00 \pm 0.00$ \\
\hline & Pawpaw & $0.00 \pm 0.00$ & $8.80 \pm 1.16$ & $0.00 \pm 0.00$ \\
\hline & Black pepper & $0.00 \pm 0.00$ & $5.60 \pm 1.36$ & $0.00 \pm 0.00$ \\
\hline
\end{tabular}

The results of the work show that the sensitivities of Enterobacter cloacae and Klebsiella pneumoniae were not significantly $(\mathrm{P}<0.05)$ different from each other but significantly $(\mathrm{P}<0.05)$ different from the others whose sensitivities were not different from one another. Extract source and method of extraction also affected to a degree, the efficacy of the plant extracts. Grape fruit peel as an extract source was significantly $(\mathrm{P}<0.05)$ different from black pepper seed while hot water method of extraction was significantly $(\mathrm{P}<0.05)$ different from the ethanolic method of extraction. It is worthy to note as reported by Ekwenye and Elegalam (2005) that the antimicrobial activities of these plant extracts were dependent on their concentration. Table 1 shows how the micro organisms responded to the different extract concentrations. Enterobacter cloacae was the most sensitive to all the concentrations except $0.4 \mathrm{~g} / \mathrm{ml}$ (Klebsiella pneumoniae). The sensitivities of the two most sensitive organisms (Escherichia coli and Pseudomonas lundensis) were not significantly different from each other but were from the rest. Table 2 shows the antimicrobial sensitivity of the isolated organisms using the different methods of extraction to extract the antimicrobial compounds from the plants. Ethanolic extract of black pepper inhibited Enterobacter cloacae the most then the effect of ethanolic extract of grape peel on Klebsiella pneumoniae. This table also shows that Acinetobacter species' spoilage activity can be combated using the hot water extract of pawpaw seed. The three methods of extraction were significantly different from one another in terms of the mean inhibition zones. This further showed that hot water and ethanolic methods of extraction can be relied upon to inhibit spoilage and pathogenic organisms in catfish. The isolated micro organisms also exhibited different sensitivities to the extract concentrations used. Enterobacter cloacae was the most sensitive to all extract concentrations excluding $0.4 \mathrm{~g} / \mathrm{ml}$ to which Klebsiella pneumoniae was the most sensitive. This showed that Enterobacter cloacae could be inhibited by the plant extracts (grape fruit peel, pawpaw seeds and black pepper seeds) using both low $(0.1 \mathrm{~g} / \mathrm{ml})$ and very high $(0.5 \mathrm{~g} / \mathrm{ml})$ concentrations. This trend of inhibition could result in total elimination of the microorganisms with increased extract concentration. Acinetobacter species and Escherichia coli were the most inhibited organisms by a concentration of $0.2 \mathrm{~g} / \mathrm{ml}$ and least inhibited at the highest concentration $(0.5 \mathrm{~g} / \mathrm{ml})$ evaluated. This means that their activities and presence in fish can easily be curtailed by using low concentrations of plant extracts. The sensitivity of Bacillus megaterium increased with concentrations up to $0.4 \mathrm{~g} / \mathrm{ml}$, showing that fish spoilage by it can be put under control using plant extracts only at high concentrations. Using the mid concentration of $0.3 \mathrm{~g} / \mathrm{ml}$, the activities of Citrobacter freundii were inhibited. Bacillus subtilis, Enterobacter cloacae, Klebsiella pneumoniae, $K$. oxytoca, Proteus mirabilis, Pseudomonas lundensis and Staphylococcus aureus required very high concentrations of plant extracts for remarkable inhibition, since they exhibited highest inhibition with a concentration of $0.5 \mathrm{~g} / \mathrm{ml}$, the highest concentration used in this study.

\section{CONCLUSION}

Antimicrobial properties of extracts were affected by plant source, method of 
extraction and concentration. Ethanolic extracts gave the highest zone of inhibition and best inhibitory properties on all the organisms. Enterobacter cloacae was the most sensitive microorganism to all the plant extracts evaluated, followed by Klebsiella pneumoniae; while the least sensitive was Escherichia coli. Although, grapefruit peel was the best plant, followed by black pepper, the ethanolic extract of the latter exhibited better antimicrobial property in terms of the mean zone of inhibition. The plant extracts were unable to completely inhibit all isolated organisms at the concentrations used. This suggests that the extracts at the concentrations used in this study kept isolated microorganisms at bay; with the likelihood of complete inhibition at a much higher concentrations where a positive correlation was established between antimicrobial inhibition and extract concentration. Though the best plant was grapefruit peel and the best method of extraction was the ethanolic method, the probable combination for a much better inhibition of isolated microorganisms is the ethanolic extract of black pepper at higher concentration (particularly for those organisms whose zones of inhibition had a direct relationship with the concentration of extracts, including all the isolated organisms except E. coli and Acinetobacter species). The plant extracts were considered efficient in that they were able to put the isolated organisms, especially the pathogenic ones under check by exerting on them strong antimicrobial properties.

\section{REFERENCES}

Doyle, Elliin M. (2007) Microbial Food spoilage- Losses and Control Strategies. Food Research Institute, $\mathrm{PhD}$ Thesis, University of Wisconsin - Madison, WI 53706.

Fellers, P.J.; Nikdel, S. and Lee, H.S. (1990) Nutrient content and nutrition labelling of several processed Florida citrus juice products J. Am Diet. Assoc. 90(8): 1079- 1084.

Woedtke Von, T.; Schluter, B.; Pflegel, P.; Lindequist, U. and Julich, W.D. (1999) Aspects of the Antimicrobial efficacy of grapefruit seed extract and its relation to preservative substances contained. Pharmazie 54: 452- 456

Azu, N.C. and Onyeagba, R. A. (2007) Antimicrobial Properties of extracts Allium cepa (onions) and Zingiber officinale (ginger) on Escherichia coli, Salmonella typhi and Bacillus subtilis. The Internet Journal of tropical Medicine.3(2).1-3p

De La Cruz Medina, J., Gilber Vela Gutiérrez and García, H.S. (2003) Pawpaw: Post-harvest Operation. Edited by AGSI/FAO: Danilo Mejía, PhD, $\underline{\text { AGST. FAO }}$ (Technical), Emanuela Parrucci

Sanders, D.H. (1990) Statistics: A Fresh Approach. $4^{\text {th }}$ edition. McGrawHill Inc., Singapore.

Ekwenye, U.N. and Elegalam, N.N. (2005) Antimicrobial activity of ginger (Zingiber officinale Roscoe) and garlic (Allium sativum L.) extracts on Escherichia coli and Salmonella typhi. Journal of Molecular Medicine and Advanced Science 1(4): 411-416. 